\title{
Fatty Acid Analysis, Chemical Constituents, Biological Activity and Pesticide Residues Screening in Jordanian Propolis
}

\author{
Rajashri R. Naik ${ }^{1}$, Ashok K. Shakya ${ }^{1,2, * \mathbb{D}}$, Ghaleb A. Oriquat ${ }^{3}$, Shankar Katekhaye ${ }^{4,5}$, Anant Paradkar ${ }^{5}$, \\ Hugo Fearnley ${ }^{4}$ and James Fearnley ${ }^{6}$
}

1 Faculty of Pharmacy, Al-Ahliyya Amman University, Amman 19328, Jordan; rsharry@ammanu.edu.jo

2 Pharmacological \& Diagnostic Research Center, Faculty of Pharmacy, Al-Ahliyya Amman University, Amman 19328, Jordan

3 Faculty of Allied Medical Sciences, Al-Ahliyya Amman University, Amman 19328, Jordan; goreqat@ammanu.edu.jo

4 Natures Laboratory Ltd., Whitby YO22 4NH, UK; s.katekhaye@bradford.ac.uk (S.K.); hugo.fearnley@beevitalpropolis.com (H.F.)

5 Centre for Pharmaceutical Engineering Science, School of Pharmacy, University of Bradford, Bradford BD7 1DP, UK; a.paradkar1@bradford.ac.uk

6 Apiceutical Research Centre, 3b Enterprise Way, Whitby YO22 4NH, UK; james.fearnley@beevitalpropolis.com

* Correspondence: ak_shakya@ammanu.edu.jo; Tel.: +962-5-3500211 (ext. 2315)

check for

updates

Citation: Naik, R.R.; Shakya, A.K.; Oriquat, G.A.; Katekhaye, S.; Paradkar, A.; Fearnley, H.; Fearnley, J. Fatty Acid Analysis, Chemical Constituents, Biological Activity and Pesticide Residues Screening in Jordanian Propolis. Molecules 2021, 26 , 5076. https://doi.org/10.3390/ molecules26165076

Academic Editor: Zhentian Lei

Received: 21 July 2021

Accepted: 17 August 2021

Published: 21 August 2021

Publisher's Note: MDPI stays neutral with regard to jurisdictional claims in published maps and institutional affiliations.

Copyright: (c) 2021 by the authors. Licensee MDPI, Basel, Switzerland. This article is an open access article distributed under the terms and conditions of the Creative Commons Attribution (CC BY) license (https:/ / creativecommons.org/licenses/by/ $4.0 /)$.
Abstract: Propolis is a resinous natural product collected by honeybees (Apis mellifera and others) from tree exudates that has been widely used in folk medicine. The present study was carried out to investigate the fatty acid composition, chemical constituents, antioxidant, and xanthine oxidase (XO) inhibitory activity of Jordanian propolis, collected from Al-Ghour, Jordan. The hexane extract of Jordanian propolis contained different fatty acids, which are reported for the first time by using GC-FID. The HPLC was carried out to identify important chemical constituents such as fatty acids, polyphenols and $\alpha$-tocopherol. The antioxidant and xanthine oxidase inhibitory activities were also monitored. The major fatty acid identified were palmitic acid (44.6\%), oleic acid (18:1 $\Delta^{9} \mathrm{cis}$, $24.6 \%)$, arachidic acid $(7.4 \%)$, stearic acid $(5.4 \%)$, linoleic acid $\left(18: 2 \Delta^{9-12}\right.$ cis, $\left.3.1 \%\right)$, caprylic acid (2.9\%), lignoceric acid (2.6\%), cis-11,14-eicosaldienoic acid (20:2 $\Delta^{11-14}$ cis, $\left.2.4 \%\right)$, palmitoleic acid (1.5\%),

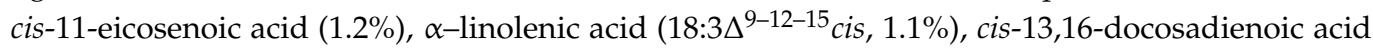
$\left(22: 2 \Delta^{13-16} c i s, 1.0 \%\right)$, along with other fatty acids. The major chemical constituents identified using gradient HPLC-PDA analysis were pinocembrin (2.82\%), chrysin (1.83\%), luteolin-7-O-glucoside $(1.23 \%)$, caffeic acid $(1.12 \%)$, caffeic acid phenethyl ester (CAPE, $0.79 \%)$, apigenin $(0.54 \%)$, galangin $(0.46 \%)$, and luteolin $(0.30 \%)$; while the minor constituents were hesperidin, quercetin, rutin, and vanillic acid. The percentage of $\alpha$-tocopherol was $2.01 \mu \mathrm{g} / \mathrm{g}$ of the lipid fraction of propolis. Antioxidant properties of the extracts were determined via DPPH radical scavenging. The DPPH radical scavenging activities $\left(\mathrm{IC}_{50}\right.$ ) of different extracts ranged from 6.13 to $60.5 \mu \mathrm{g} / \mathrm{mL}$ compared to ascorbic acid $(1.21 \mu \mathrm{g} / \mathrm{mL})$. The xanthine oxidase inhibition ( $\left.\mathrm{IC}_{50}\right)$ ranged from 75.11 to $250.74 \mu \mathrm{g} / \mathrm{mL}$ compared to allopurinol $(0.38 \mu \mathrm{g} / \mathrm{mL})$. The results indicate that the various flavonoids, phenolic compounds, $\alpha$-tocopherol, and other constituents which are present in propolis are responsible for the antioxidant and xanthine oxidation inhibition activity. To evaluate the safety studies of propolis, the pesticide residues were also monitored by LC-MS-MS 4500 Q-Trap. Trace amounts of pesticide residue $(\mathrm{ng} / \mathrm{mL})$ were detected in the samples, which are far below the permissible limit as per international guidelines.

Keywords: propolis; GC-FID; LC-MS-MS; HPLC-PDA; desmedipham; pinocembrin; chrysin; caffeic acid phenyl ester; antioxidant; xanthine oxidase inhibition 


\section{Introduction}

Propolis is a resinous natural product collected by honeybees (such as Apis mellifera and others) from tree exudates or resins with bee-wax along with salivary secretions used in natural medicine for long time. Bees use the propolis to repair the cracks and strengthen the walls of the hives to create a narrow and defendable entry into the hive. Bees also use propolis to polish the interior of their hives to control the proliferation of pathogenic microorganisms. Propolis also helps to remove the entry of intruders and to fix their corpses [1].

Many pharmacological activities of propolis are well documented, such as free radical scavenging, antioxidant, anticancer, anti-bacterial, anti-inflammatory, hepato-protective, radio-protective and neuro-protective [2-6]. The pharmacological and biological effects of propolis depend on their geographical location, altitude, time of collection, season and the species of the bee. The chemical composition of propolis from differing geographic regions is well recorded in the literature [7-12]. There are major chemical differences between propolis from China, India, Chile, South Africa, Taiwan and other countries [7-10]. Due to above mentioned factors, the chemical composition of the propolis is highly variable. The color, flavor and texture also vary from season to season. Due to the wide diversity of propolis, it is always in demand to explore for its pharmacological and biological activity [10-12].

In general, the propolis contains flavonoids and terpenes, as these chemical constituents are present in the flowers and other parts of the plant. Cuban propolis contains polyisoprenylated benzophenones, while the Brazilian propolis contains derivatives of acetophenone and p-coumaric acid. Chilean propolis contains benzopyran, phenylpropane and other aromatic aldehydes and derivatives [13].

In pre-Columbian culture the consumption of honey and culture of Melipona beecheii (bee without sting) was very common. During the 15th century the beekeeping was developed with the European bee (Apis mellifera). Jordanian propolis contains chemical compounds such as 4(Z)-1-3-dihydroxyeupha-7,24-dien-26-oic acid [2], along with other compounds such as pinobanksin-3-O-acetate, pinocembrin and chrysin [3] and lignoceric acid [2]. It has been reported that other propolis contains chrysin and kaempferol, which are used as anti-aging agents due to their antioxidant activity [14-19]. Since ancient times, propolis has been used for its therapeutic potentials in various ailments. It still exists in some of the traditional medicines in Eastern Europe and some parts of the world. Based on this, studies are ongoing in many parts of the world on the biological properties of propolis, due to which it has been used in various therapeutical applications, such as ointments and creams to heal wounds, treat burns and skin problems and ulcers. Various forms of propolis preparations have also been used in the treatment of laryngological problems, gynaecological diseases, asthma and diabetes, and it is also used in toothpaste and mouthwash preparations to combat gingivitis and stomatitis. There is a considerable amount of reported literature on the use of propolis in cosmetics for lotions, face creams and solutions [20-22].

Literature surveys have shown that the fatty acid composition and biological activity of Jordanian propolis has not been explored in great detail, hence it was thought worthwhile to study the composition of Jordanian propolis and explore its antioxidant and xanthine oxidase inhibitor activity.

\section{Results and Discussion}

\subsection{Determination of Fatty Acid Methyl Esters (FAME) by GC-FID}

As mentioned earlier, propolis is a resinous nontoxic product of the hive, primarily resin collected by honeybees from trees and plants. Propolis is known to have several health benefits for human beings and has been used since time immemorial $[23,24]$. The pharmacological and the chemical composition of propolis may vary significantly depending on the geographical location, time and seasonal variations $[7,25]$. The present study was carried out to investigate the fatty acid composition, antioxidant and xanthine oxidase inhibitory 
activity of Jordanian propolis. Propolis was collected from the Al-Ghour region of the Jordan. The analysis was carried out by GC-FID and 19 compounds were identified. Most of the compounds that were identified are presented in Table 1. Different fatty acid methyl esters of the propolis were identified using standard FAME which contains 37 methyl esters of $\mathrm{C}_{4}-\mathrm{C}_{24}$ fatty acid. The hexane extract of Jordanian Propolis contains different fatty acids, some of which are reported for the first time. The major fatty acid identified were palmitic acid $(44.5 \%)$, oleic acid $\left(18: 1 \Delta^{9}\right.$ cis, $\left.24.6 \%\right)$, arachidic acid $(7.4 \%)$, stearic acid $(5.4 \%)$, linoleic acid (18:2 $\Delta^{9-12}$ cis, 3.1\%), caprylic acid (2.9\%), lignoceric acid (2.6\%), cis-11,14-eicosadienoic acid $\left(20: 2 \Delta^{11-14}\right.$-cis, $\left.2.4 \%\right)$, palmitoleic acid (1.5\%), cis-11-eicosenoic acid $(1.2 \%)$, $\alpha$-linolenic

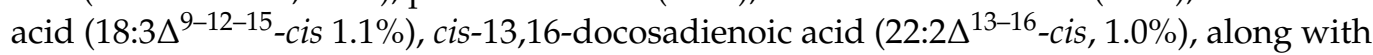
other fatty acids (Figure 1). Fatty acids such as oleic (18:1), palmitic (16:0), linoleic (18:2), and stearic (18:0), were reported by Castro et al. and Duarte et al. [26,27] in propolis samples. A total of 10 compounds were identified by Thirugnanasampandan et al. [28] from the propolis collected from the Tamilnadu region of India, using GC-MS to show the presence of fatty acids. Among 10 compounds the major fatty acid present were as 9-octadecenoic acid (3.2\%), decanoic acid (2.12\%) 9,12-hexadecadienoic acid (1.29\%), octadecadienoic acid methyl ester $(0.49 \%)$ and alcohols such as 1-tetradecanol $(0.89 \%)$, octadecanol (0.69\%), 1-dotricontanol (0.48\%) and 2,3-epoxy-5,8-hectadecadien-1-ol (0.6\%) [28]. Fourteen fatty acid methyl esters were identified by GC-MS method in propolis by Sahinler and Kaftanoglu [29]. FAME identified were hexadecanoic acid, 9-octadecanoic acid, docosanoic acid, tetracosanoic acid, hexacosanoic acid, octacosanoic acid, triacontanoic acid, octadecanoic acid, 8-octadecanoic acid, 9,12,15-octadectrienoic acid, hexacosanoic acid, 9,12-octadecanoic acid and pentanoic acid methyl esters. Hegazi and El Hady [30] analyzed the chemical constituents of propolis from different province of Egypt using GC-MS, they reported 71 compounds of which 14 were new to propolis. In other study, they have reported 75 compounds of which 22 were new to propolis [31]. In both the studies the percent composition of the chemical constituents varied from different region of the province. Around 50 individual compounds were identified by Popova et al. [32] in the propolis collected from Oman. These compounds include sugars, polyols, hydroxy acids, fatty acids, cardanols and cardols, anacardic acids, flavan derivatives, triterpenes, prenylated flavanones and chalcones. They observed that not all propolis were similar in their chemical profiling. Most of the available reports are based on the GC-MS. We have identified for the first time 19 compounds by GC-FID. Composition and concentration showed significant disparity between the types of propolis which may be attributed to the geographical location, time, and seasonal variation. Bankova et al. [33] demonstrated that the plant source of the propolis differs significantly even in the same beehive and in the same season. Due to this disparity in the chemical constituents there may be difference in the biological activity such as antioxidant and xanthine oxidase activity.

\subsection{Analysis of Chemical Constituents Using HPLC-PDA}

The major chemical constituents identified using gradient HPLC-PDA analysis were pinocembrin $(2.82 \%)$, chrysin $(1.83 \%)$, luteolin-7-O-glucoside $(1.23 \%)$, caffeic acid $(1.12 \%)$, caffeic acid phenethyl ester (CAPE, $0.79 \%)$, apigenin $(0.54 \%$, galangin $(0.46 \%)$, luteolin $(0.30 \%)$ and minor constituents such as hesperidin, quercetin, rutin, vanillic acid (Table 2 and Figure 2). The percentage of $\alpha$-tocopherol was $2.01 \mu \mathrm{g} / \mathrm{g}$ of lipid fraction of propolis. Romero et al. [34] identified 21 compounds in Brazilian propolis. The identified compounds were (1) caffeic acid, (2) p-coumaric acid, (3) ferulic acid, (4) 3,4-dimethylcaffeic acid, (5) pinobanksin-5-methyl-ether, (6) kaempferide, (7) apigenin, (8) kaempferol, (9) cinnamilidenacetic acid, (10) caffeic acid prenyl ester, (11) chrysin, (12) pinocembrin, (13) galangin, (14) caffeic acid phenylethyl ester, (15) pinobanksin-3-O-acetate, (16) pcoumaric prenyl ester, (17) p-coumaric cinnamyl ester, (18) pinobanksin-3-O-butyrate, (19) pinobanksin-3-O-pentanoate, (20) pinobanksin-3-O-hexanoate, and (21) p-methoxy cinnamic acid cinnamyl ester. 
$\mathrm{mV}$

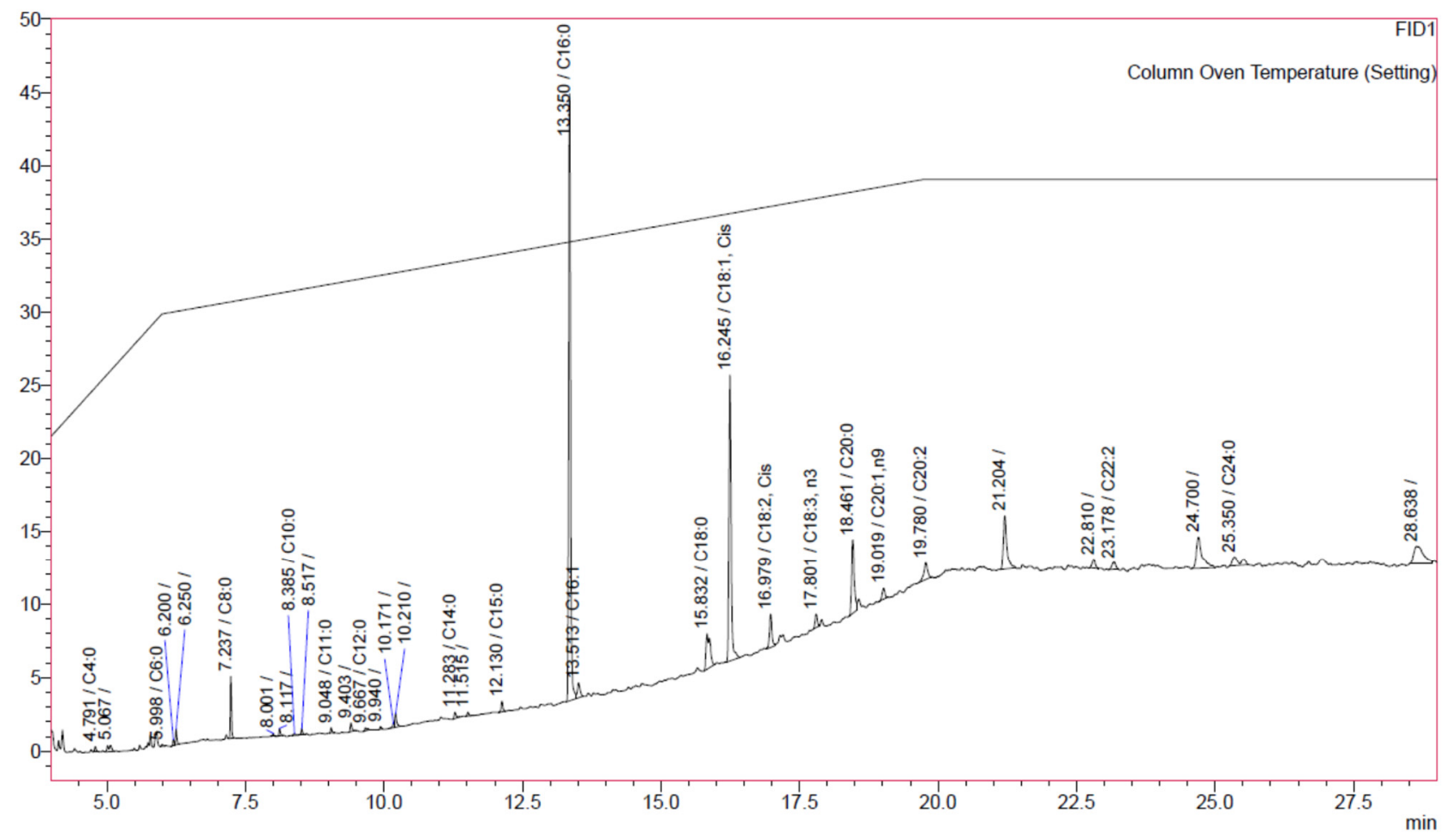

Figure 1. GC-FID analysis of Jordanian propolis sample, showing different identified FAME.

Table 1. Fatty acid composition of propolis.

\begin{tabular}{|c|c|c|c|}
\hline Time & Formula & Name (Identified as FAME) & Relative Percentage * \\
\hline 4.791 & C4:0 & Butyric acid & 0.34 \\
\hline 5.998 & C6:0 & Caproic acid & 0.08 \\
\hline 7.237 & C8:0 & Caprylic acid & 2.93 \\
\hline 8.385 & C10:0 & Capric acid & 0.13 \\
\hline 9.048 & C11:0 & Undecanoic acid & 0.29 \\
\hline 9.667 & $\mathrm{C} 12: 0$ & Lauric acid & 0.24 \\
\hline 11.283 & C14:0 & Myristic acid & 0.47 \\
\hline 12.131 & $\mathrm{C} 15: 0$ & Pentadecanoic acid & 0.70 \\
\hline 13.351 & C16:0 & Palmitic acid & 44.55 \\
\hline 15.832 & C18:0 & Stearic acid & 5.42 \\
\hline 18.461 & C20:0 & Arachidic acid & 7.36 \\
\hline \multirow[t]{2}{*}{25.351} & C24:0 & Lignoceric acid & 2.59 \\
\hline & & $\Sigma$ SFA $^{a}$ & 65.10 \\
\hline 13.513 & C16:1 & Palmitoleic acid & 1.52 \\
\hline 16.245 & $\mathrm{C} 18: 1$, cis & Oleic acid & 24.57 \\
\hline \multirow[t]{2}{*}{19.019} & C20:1, n9 & cis-11-Eicosenoic acid & 1.15 \\
\hline & & $\Sigma_{\text {MUFA }^{b}}$ & 27.24 \\
\hline 16.979 & $\mathrm{C} 18: 2$, cis & Linoleic acid & 3.08 \\
\hline 17.801 & $\mathrm{C} 18: 3, \mathrm{n} 3$ & $\alpha$-Linolenic acid & 1.13 \\
\hline 19.78 & C20:2 & cis-11,14-Eicosadienoic acid & 2.40 \\
\hline 23.178 & $\mathrm{C} 22: 2$ & cis-13,16-Docosadienoic acid & 1.05 \\
\hline & & $\Sigma_{\text {PUFA }}^{c}$ & 7.66 \\
\hline
\end{tabular}

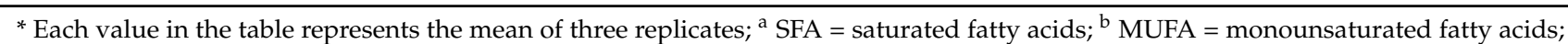

${ }^{\mathrm{c}}$ PUFA = polyunsaturated fatty acids . 
Table 2. Chemical constituents identified by HPLC-PDA in propolis sample collected from Jordan.

\begin{tabular}{ccc}
\hline Time (min) & Name & Relative Percentage \\
\hline 4.900 & Gallic acid & - \\
9.789 & Chlorogenic acid & 0.026 \\
10.632 & Vanillic acid & 0.035 \\
11.039 & Caffeic acid & 1.124 \\
15.216 & Rutin & 0.036 \\
16.372 & Lueolin-7-O-glucoside & 1.237 \\
17.662 & Naringenin & 0.005 \\
18.279 & Apigenin-7-O-glucoside & 0.037 \\
18.917 & Rosmarinic acid & 0.002 \\
19.583 & 4-hydroxy coumaric acid & 0.026 \\
22.446 & Luteolin & 0.301 \\
22.774 & Quercetin & 0.063 \\
26.258 & Apigenin & 0.540 \\
32.023 & Pinocembrin & 2.819 \\
34.328 & Chrysin & 1.828 \\
340823 & CAPE & 0.790 \\
35.659 & Galangin & 0.462 \\
39.257 & Carnosic acid (used as IS) & - \\
45.847 & Hesperidin & 0.103 \\
\hline
\end{tabular}

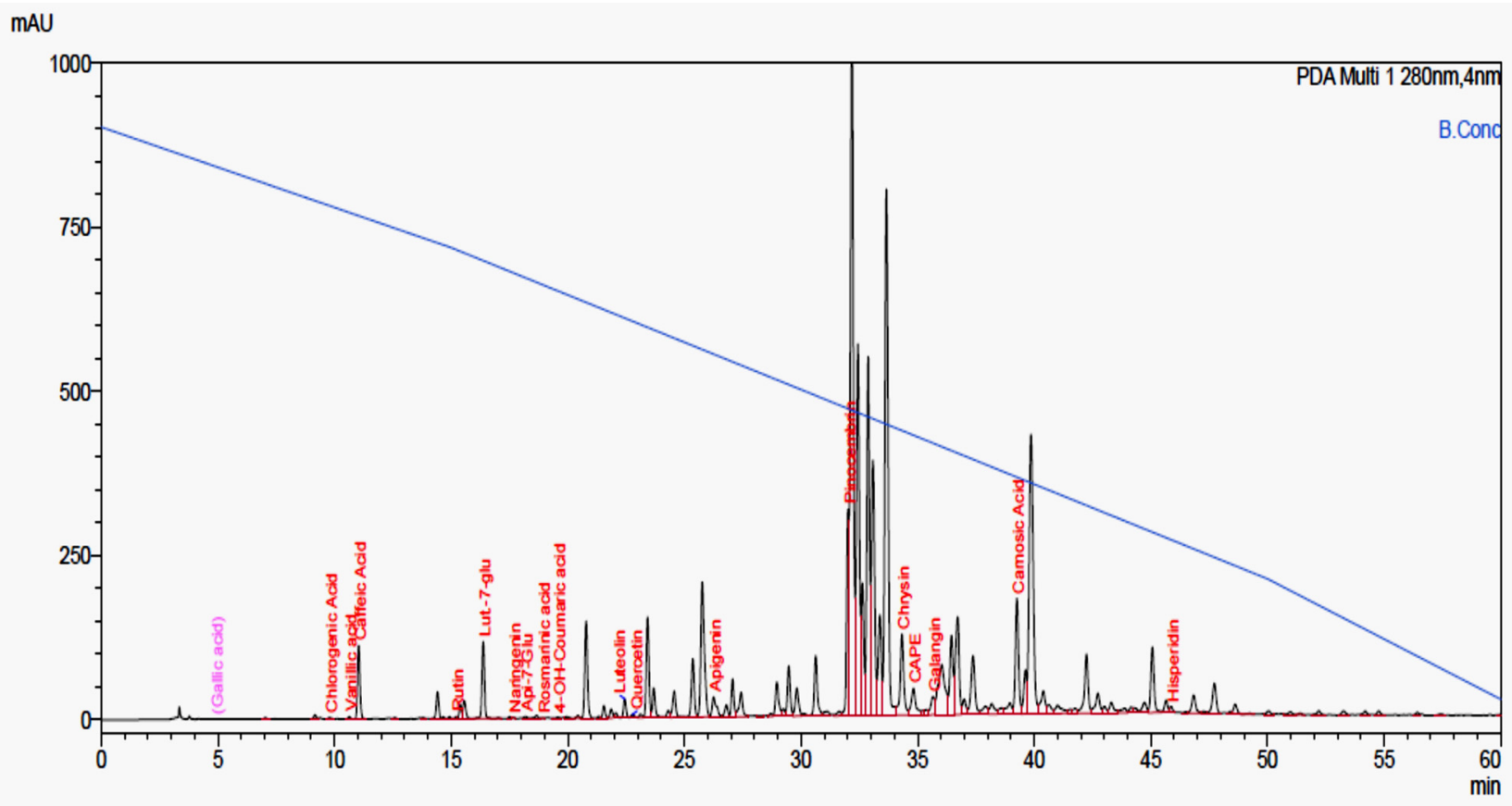

Figure 2. HPLC-PDA analysis of Jordanian propolis sample (70\% ethanolic extract), showing different identified chemical constituents.

\subsection{LC-MS-MS Screening for Pesticide Residues in Propolis}

The propolis was screened for more than 400 pesticides using the QuEChERS method according to ABSciEx guidelines. All the targeted analyses were carried out using the LCMS-MS-4500-QTrap. The QuEChERS method (Quick-Easy-Cheap-Effective-Rugged-Safe extraction) has been developed for the determination of pesticide residues using earlier reported methods [35]. This is the first report on Jordanian propolis which shows the presence of trace amount of pesticide residues (in $\mathrm{ng} / \mathrm{mL}$ concentration) in natural product. The propolis contains (trace amount of) desmedipham (37.41 \pm 0.70$)$, fenpropomorph $(21.52 \pm 0.51)$, dichlfenthion $(15.83 \pm 0.33)$ and etoxazole $(20.94 \pm 0.25) \mathrm{in} \mathrm{ng} / \mathrm{mL}$ concen- 
tration which might be due to the use of the pesticide in the country side (Table 3 and Figure 3). The amount of pesticide residues in the propolis is within the acceptable range as per guideline [36-39].

Table 3. LC-MS-MS analysis of pesticide in the propolis.

\begin{tabular}{cc}
\hline Pesticide & Concentration $(\mathbf{n g} / \mathbf{m L}) *$ \\
\hline Desmedipham & $37.41 \pm 0.70$ \\
Fenpropomorph & $21.52 \pm 0.51$ \\
Dichlofenthion & $15.83 \pm 0.33$ \\
Etoxazole & $20.94 \pm 0.25$ \\
\hline
\end{tabular}<smiles>CCOC(=O)Nc1cccc(OC(=O)Nc2ccccc2)c1</smiles>

(a)<smiles>CCOP(=S)(OCC)Oc1ccc(Cl)cc1Cl</smiles>

(c)<smiles>CC(Cc1ccc(C(C)(C)C)cc1)CN1CC(C)OC(C)C1</smiles>

(b)

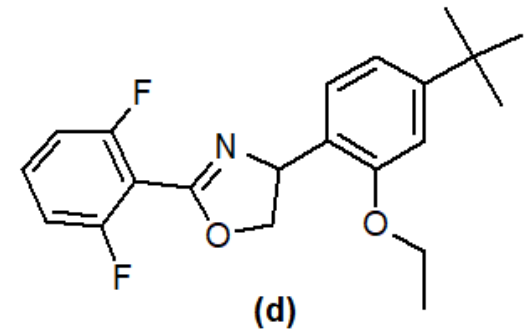

Figure 3. Chemical Structure of pesticides detected in the propolis sample, (a) desmedipham, (b) fenpropomorph, (c) dichlofenthion and (d) etoxazole.

\subsection{Biological Activity}

\subsubsection{DPPH Radical Scavenging Activity}

One of the important characteristics of propolis is its antioxidant and antiradical activity [9]. Antioxidant properties of the different extracts were determined via DPPH radical scavenging, $\beta$-carotene bleaching assay and $\mathrm{NO}$ scavenging assay. The extract produced significant antioxidant activity in vitro with free radical scavenging activity with $\mathrm{IC}_{50}$ value of $6.13 \pm 0.1,14.4 \pm 0.1$ and $60.5 \pm 0.1 \mu \mathrm{g} / \mathrm{mL}$ of the $70 \%$ ethanolic, $50 \%$ ethanolic and lipid extraction (Table 4). The $\mathrm{IC}_{50}$ values for ascorbic acid (in 50\% ethanol) and $\alpha$-Tocopherol (in hexane) were $1.21 \pm 0.03$ and $85.5 \pm 1.7 \mu \mathrm{g} / \mathrm{mL}$ respectively. Similar results were reported by Bankova et al. (2019) [33] in the Romanian propolis with significant scavenging activity positively correlated to the presence of flavonoids. Similar observations were made by da Silva et al. (2006) [40] and Ahn et al. (2007) [41] on Brazilian and Chinese propolis respectively. Similar results were reported by Thirugnanasampandan et al. on the antioxidant activity of Indian propolis [28]. It may be noted that the propolis from different geographical locations exhibit antioxidant activity despite the disparity or difference in their chemical composition [33,42]. The antioxidant activity in the propolis may be attributed to the presence of major compounds such as flavonoids and phenolic acids. These compounds are useful as natural antioxidants and prevent oxidative damage of DNA caused by ROS [43]. The antioxidant effect may be due to the scavenging activity of the free radical and the interaction with enzymes. As reported by Moreira et al. (2008) [44] 
some of the chemical components of the propolis are absorbed and circulated in the blood and these compounds act as hydrophilic antioxidants and save vitamin C. Several bee products also exhibit the antioxidant activity which is attributed to the presence of flavonoids [45].

Table 4. In vitro DPPH radical scavenging and XO activity of propolis.

\begin{tabular}{ccc}
\hline Sample & \multicolumn{2}{c}{ IC $_{\mathbf{5 0}}(\boldsymbol{\mu g} / \mathrm{mL})$} \\
\cline { 2 - 3 } & DPPH Radical Activity * & XO Activity of Propolis * \\
\hline Propolis (70\% ethanolic extract) & $6.13 \pm 0.1$ & $75.11 \pm 11.43$ \\
Propolis (50\% ethanolic extract) & $14.4 \pm 0.1$ & $89.51 \pm 17.40$ \\
Propolis (hexane extract, Lipid Fraction) & $60.5 \pm 0.1$ & $250.74 \pm 13.09$ \\
Ascorbic Acid (in 50\% ethanol) & $1.21 \pm 0.03$ & - \\
$\alpha$-Tocopherol (in hexane) & $85.5 \pm 1.7$ & - \\
Allopurinol & - & $0.38 \pm 0.08$ \\
\hline
\end{tabular}

\subsubsection{In Vitro Xanthine Oxidase Inhibition Activity}

There is not much literature available on the inhibitory activity of propolis on xanthine oxidase and treatment of gout. The propolis extracts exhibited appreciable xanthine oxidase inhibitory activity in vitro. Results of the xanthine oxidase (XO) activity is presented in the Table 4 and the results are expressed as inhibitory concentration $(\mu \mathrm{g} / \mathrm{mL})$. It was observed that the extracts inhibited the xanthine oxidase with $\mathrm{IC}_{50}$ value of $75.11 \pm 11.43$, $89.51 \pm 0.17 .40$ and $250.74 \pm 13.09 \mu \mathrm{g} / \mathrm{mL}$ of the $70 \%$ ethanolic, $50 \%$ ethanolic and lipid fraction respectively. The lower $\mathrm{IC}_{50}$ value in $70 \%$ ethanolic extract might be due to the presence of hydrophilic as well as lipophilic compounds. The value of standard compound allopurinol against xanthine oxidase was $0.36 \pm 0.08 \mu \mathrm{g} / \mathrm{mL}$. Similar inhibitory activity was reported by Russo et al. [46] due to the presence of CAPE and galangin. In eukaryotic cell xanthine oxidase is an enzyme that is the source of superoxide anions. Most of the natural compound such as some polyphenols exhibit a dose dependent inhibition of xanthine oxidase [47]. One of the characteristic of the ischemic injury is the over production of superoxide anion due to the leak of electron in the mitochondrial respiratory chain and due to the generation by the conversion of xanthine dehydrogenase to xanthine oxidase that produce superoxide anion when it oxidizes xanthine into uric acid [48]. Flavonoids and phenolic acids may be one of the potent inhibitor against the metabolic enzymes such as cyclo-oxygenase, xanthine oxidase and lipo-oxygenase [49], which can control the diseases such as inflammation, hyperuricemia and gout. Hence compounds such as flavonoids and flavones glycoside such as rutin, luteolin, luteolin-7-O-glucoside, quercetin, apigenin, pinocembrin, chrysin, CAPE, galangin and hesperidin, may have a role in the inhibition of $\mathrm{XO} . \mathrm{XO}$ inhibitor and uricosuric agents are used in the treatment of diseases such as gouty arthritis and inflammatory disease. The drug allopurinol is used in the treatment of gout, but these drugs are associated with minor side effects [50], hence drug with lesser side effect and more therapeutic activity is required.

\section{Materials and Methods}

The $\mathrm{DPPH}^{\bullet}$, 4-hydroxy coumaric acid, apigenin, apigenin-7-O-glucoside, caffeic acid, CAPE, carnosic acid (used as IS), chlorogenic acid, chrysin, galangin, gallic acid, hesperidin, lueolin-7-O-glucoside, luteolin, naringenin, pinocembrin, quercetin, rosmarinic acid, rutin, vanillic acid, xanthine oxidase (Bovine), allopurinol, xanthine, were procured from SigmaAldrich (St. Louis, MO, USA). Thirty-seven methyl esters of $\mathrm{C}_{4}-\mathrm{C}_{24}$ fatty acids, ascorbic acid, $\alpha$-tocopherol of analytical grade were purchased from Sigma-Aldrich Chem. Co. (St. Louis, MO, USA). 


\subsection{Collection of Samples}

Jordanian propolis was purchased from a local market. The propolis was originally collected from beehives located at Al-Ghour region in Jordan from March to July 2018 using propolis collectors. Propolis from the collectors was gathered and kept at $20^{\circ} \mathrm{C}$ until processed. The ground propolis $(10 \mathrm{~g})$ was extracted with $100 \mathrm{~mL}$ of ethanol (either $70 \%$ or $50 \%)$ or with hexane at $25^{\circ} \mathrm{C}$ for $48 \mathrm{~h}(n=3)$. The extracts were then filtered through a Whatman no. 1 filter paper and the solvent was evaporated using Buchi R-100 Rotary Evaporator (BÜCHI Labortechnik AG, Flawil, Switzerland). The samples were stored under nitrogen till use.

\subsection{Analysis of Samples}

The extracts were concentrated by vacuum evaporation, reconstituted and then filtered by syringe filter with a $0.22 \mathrm{~mm}$ membrane. The extracts were then tested for chemical constituents using GC-FID, and high-performance liquid chromatography (HPLC). The $\alpha$ tocopherol content was determined in the lipid fraction (hexane extract). For the monitoring of pesticide residues, a crude sample of propolis was used.

\subsubsection{Determination of Fatty Acid Methyl Esters (FAME) by GC-FID}

FAME was synthesized by using sodium methoxide in presence of methanol at $40^{\circ} \mathrm{C}$. In brief, a solution of fixed oil $(0.1 \mathrm{~g})$ in methanol $(25 \mathrm{~mL})$, sodium methoxide solution $(30 \%$ $w / v$ in methanol, $0.15 \mathrm{~g}$ ) was added with stirring. The reaction mixture was maintained at $40^{\circ} \mathrm{C}$ for $45 \mathrm{~min}$ with constant shaking using Memmert water bath and shaker (Memmert GmbH Co. KG, Schwabach, Germany). Twenty-five milliliters of $n$-hexane was added, and the solution was shaken for $20 \mathrm{~min}$. The reaction was stopped using saturated solution of oxalic acid. The precipitated sodium oxalate was removed after centrifuging the mixture at $5000 \times g \mathrm{rpm}$ for fifteen minutes. The supernatant was collected and dried over anhydrous sodium sulphate and were analyzed by GC-FID for FAME.

FAME samples were analyzed using gas chromatograph (Model 2030, Nexera, Shimadzu, Japan) [51]. The instrument is equipped with DB-23 capillary column with thickness of the film of $0.25 \mu \mathrm{m}$, length of $60 \mathrm{~m}$, and $0.250 \mathrm{~mm}$ internal diameter. The optimum conditions for operating the GC with respect to temperature were as follows: initial temperature of the oven was maintained at $50{ }^{\circ} \mathrm{C}$ for $1 \mathrm{~min}$ and then raised to $175^{\circ} \mathrm{C}$ (@25 ${ }^{\circ} \mathrm{C} / \mathrm{min}$ ) then it was raised to $230\left(@ 4{ }^{\circ} \mathrm{C} / \mathrm{min}\right)$, there after the temperature was maintained at $230^{\circ} \mathrm{C}$ for $10 \mathrm{~min}$, separation of analytic were achieved by carrier gas (He) at a Linear velocity of $33 \mathrm{~cm} / \mathrm{s}$. The injection volume of samples was $1 \mu \mathrm{L}$ and the split ratio was 1:50. The injector port and the detectors were maintained at a temperature of $280{ }^{\circ} \mathrm{C}$ with a total run time of $40 \mathrm{~min}$. The signals were recorded using Windows 7 based GC solution software (Version 1.25, Shimadzu Corporation, Kyoto, Japan) and the data were analyzed. Different fatty acid methyl esters of the propolis were identified, using standard FAME which contains 37 methyl esters of $\mathrm{C}_{4}-\mathrm{C}_{24}$ fatty acid (Sigma-Aldrich Chem. Co., St. Louis, MO, USA). The results of the three independent reactions were averaged on the basis of three different experiments.

\subsubsection{HPLC-PDA Analysis of Propolis}

Determination of Chemical Constituents

Phenolic compounds in the samples of propolis (70\% ethanolic extract) were identified and quantified using a Nexera-2030-3D integrated HPLC instrument (Shimadzu, Kyoto, Japan) equipped with a quaternary pump and a PDA detector, sample cooler and column oven. Quantitative and qualitative analyses were carried on Hypersil-Gold C18 column (4.6 mm i.d. $\times 250 \mathrm{~mm}, 5.0 \mu \mathrm{m}$ particle size, Thermo-Fisher, Waltham, MA, USA). Chromatograms were acquired between 190 to $400 \mathrm{~nm}$ and processed using the tools of the Lab Solution software (Shimadzu Corporation, Kyoto, Japan). The flow rate used for elution was $1 \mathrm{~mL} / \mathrm{min}$ and signals were monitored by UV detection at $280 \mathrm{~nm}$. The sample injection volume was $10 \mu \mathrm{L}$. The solvent system was $2 \%(v / v)$ glacial acetic acid 
in water (solvent A) and acetonitrile (solvent B). The gradient elution program was as follows: initially 95\% A (v/v) and 5\% B at $0-1 \mathrm{~min}, 95-75 \% \mathrm{~A}(v / v)$ at $1-15 \mathrm{~min}, 75-20 \% \mathrm{~A}$ $(v / v)$ at $15-50 \mathrm{~min}, 20-0 \% \mathrm{~A}(v / v)$ at $50-60 \mathrm{~min}, 0 \% \mathrm{~A}(v / v)$ was maintained up to $63 \mathrm{~min}$, thereafter $0-95 \% \mathrm{~A}(v / v)$ at $63-68 \mathrm{~min}$ and then $95 \% \mathrm{~A}(v / v)$ was maintained up to $74 \mathrm{~min}$. Identification of the compounds in the chromatograms were performed by the comparison of their retention times, UV spectra and peak purity profile with those of reference standards. Determination of each phenolic compound was performed using the corresponding calibration curve. Extract samples were injected three times for HPLC analysis.

Determination of $\alpha$-Tocopherol in Lipid Fraction

$\alpha$-Tocopherol content in the lipid fraction was determined using the procedure described earlier [51]. Briefly, the separation of different isomers and quantization was carried out using BDS-Hypersil column $(150 \mathrm{~mm} \times 4.6 \mathrm{~mm}, 5 \mu \mathrm{m})$ using a mixture of methanol and acetonitrile $(50: 50, v / v)$ as mobile phase (flow rate $-1 \mathrm{~mL} / \mathrm{min}$ ). The signals of analyte were captured using PDA detector and quantitated at $290 \mathrm{~nm}$ using LC-solution (Version 1.25, Shimadzu Corporation, Kyoto, Japan) software, after injecting $5 \mu \mathrm{L}$ of different standard and test sample. The $\alpha$-tocopherol content was calculated in the oil from the calibration curve.

\subsubsection{LC-MS-MS Screening for Pesticide Residues in Propolis}

The propolis was screened for more than 400 pesticide residues using in-house developed QuEChERS method according to ABSciEx guideline using LC-MS-MS 4500-QTrap (ABSciex USA, AB Sciex LLC, Framingham, MA, USA). QuEChERS method has been developed for the determination of pesticide residues using earlier reported methods [35].

\subsection{Biological Activity}

\subsubsection{DPPH Radical Scavenging Activity}

The samples of the propolis were analyzed for its free radical scavenging activity using DPPH radical according to the reported method with slight modification [52]. To perform the analysis, the solution of DPPH radical $(0.008 \mathrm{~g} \%)$ was prepared freshly in ethanol (95\%) or normal hexane. Different concentrations of extracts or lipid fractions of samples $(1000 \mu \mathrm{g} / \mathrm{mL}$ to $1.95 \mu \mathrm{g} / \mathrm{mL})$ in methanol or hexane were prepared. The DPPH radical $(1 \mathrm{~mL})$ solution and the samples $(1 \mathrm{~mL})$ were mixed and vortexed for $45 \mathrm{~s}$, and kept in dark at $25 \pm 2{ }^{\circ} \mathrm{C}$ for around $25 \mathrm{~min}$. The absorbance of the solutions was measured using Shimadzu UV-1800 spectrophotometer (Shimadzu, Kyoto, Japan) at $517 \mathrm{~nm}$ using hexane as blank. DPPH radical scavenging activity was determined and the $\mathrm{IC}_{50}$ was calculated as reported earlier.

\subsubsection{Xanthine Oxidase Inhibiting Activity}

$\mathrm{XO}$ inhibitory activity was measured by monitoring uric acid formation in xanthine oxidase system as described previously [53]. The assay system consisted of $0.6 \mathrm{~mL}$ phosphate buffer (100 mM; pH 7.4), $0.1 \mathrm{~mL}$ sample, $0.1 \mathrm{~mL}$ XO $(0.2 \mathrm{U} / \mathrm{mL})$, and $0.2 \mathrm{~mL}$ xanthine ( $1 \mathrm{mM}$; dissolved in $0.1 \mathrm{~N} \mathrm{NaOH})$. The reaction was initiated by adding the enzyme with or without inhibitors. Changes in absorbance of the mixture at $290 \mathrm{~nm}$ for $15 \mathrm{~min}$ compared to the absorbance of reagent blank were determined. A $0.2 \mathrm{~mL}$ aliquot of $1 \mathrm{~N} \mathrm{HCl}$ was used to stop the enzymatic reaction. Allopurinol was used as positive control.

\subsection{Statistical Analysis}

Results are expressed as mean \pm standard deviation (SD). Graph-Pad Prism 5 (GraphPad Software, San Diego, CA, USA) for Windows was used for statistical analysis of experimental data. 


\section{Conclusions}

The present study suggests that Jordanian propolis is rich in polyphenols, flavonoids and fatty acid derivatives which are responsible for their antioxidant and xanthine oxidase activity. The study also suggests that the pesticide contents were far below the permissible limit due to the controlled use of pesticides in the crops. Hence, the propolis can be exploited more for their therapeutical potential.

Author Contributions: Conceptualization, R.R.N., A.K.S., A.P., J.F. and H.F.; Data Curation, R.R.N. and A.K.S.; Formal Analysis, R.R.N. and A.K.S.; Investigation, R.R.N. and A.K.S.; Methodology, R.R.N., A.K.S., G.A.O. and S.K.; Project Administration, R.R.N. and A.K.S.; Resources, A.K.S.; Software, A.K.S.; Supervision, R.R.N., A.K.S. and G.A.O.; Validation, A.K.S.; Visualization, A.K.S.; Writing-Original Draft, R.R.N., A.K.S. and S.K.; Writing-Review and Editing, R.R.N., A.K.S., G.A.O., A.P., J.F. and H.F. All authors have read and agreed to the published version of the manuscript.

Funding: The research is supported by Deanship of Research, Al-Ahliyya Amman University, Amman Jordan through University Research Project Grant No. 1681/112/sa/r.j., dated 18 July 2019.

Institutional Review Board Statement: Not applicable.

Informed Consent Statement: Not applicable.

Data Availability Statement: No new data were created or analyzed in this study. Data sharing is not applicable to this article.

Acknowledgments: The authors wish to thank the Deanship, Faculty of Pharmacy, Medical Sciences and the Dean of Research and Higher Education, Al-Ahliyya Amman University, Amman, Jordan, for providing necessary facilities. Authors wish to thank Environmental Laboratories, Amman, Jordan for extending their facilities for pesticide monitoring in the samples.

Conflicts of Interest: The authors declare no conflict of interest.

Sample Availability: Samples are available from the communicating author.

\section{References}

1. Toreti, V.C.; Sato, H.H.; Pastore, G.M.; Park, Y.K. Recent progress of propolis for its biological and chemical compositions and its botanical origin. Evid. Based Complement. Altern. Med. 2013, 2013, 697390. [CrossRef] [PubMed]

2. Shaheen, S.A.; Zarga, M.H.A.; Nazer, I.K.; Darwish, R.M.; Al-Jaber, H.I. Chemical constituents of Jordanian propolis. Nat. Prod. Res. 2011, 25, 1312-1318. [CrossRef] [PubMed]

3. Darwish, R.M.; Zarga, M.H.; Nazer, I.K. Antibacterial effect of Jordanian propolis and isolated flavonoids against human pathogenic bacteria. Afr. J. Biotechnol. 2010, 9, 5966-5974.

4. Silici, S.; Kutluca, S. Chemical composition and antibacterial activity of propolis collected by three different races of honeybees in the same region. J. Ethnopharmacol. 2005, 99, 69-73. [CrossRef]

5. Degirmencioglu, H.T.; Guzelmeric, E.; Yuksel, P.I.; Kirmizibekmez, H.; Deniz, I.; Yesilada, E. A New Type of Anatolian Propolis: Evaluation of Its Chemical Composition, Activity Profile and Botanical Origin. Chem. Biodivers. 2019, 16, e1900492. [CrossRef]

6. Silva, F.R.G.; Matias, T.M.S.; Souza, L.I.O.; Matos-Rocha, T.J.; Fonseca, S.A.; Mousinho, K.C.; Santos, A.F. Phytochemical screening and in vitro antibacterial, antifungal, antioxidant and antitumor activities of the red propolis Alagoas. Braz. J. Biol. 2019, 79, 452-459. [CrossRef]

7. Park, Y.K.; de Alencar, S.M.; Aguiar, C.L. Botanical origin and chemical composition of Brazilian propolis. J. Agric. Food Chem. 2002, 50, 2502-2506. [CrossRef]

8. Bankova, V.S.; De Castro, S.L.; Marcucci, M.C. Propolis: Recent advances in chemistry and plant origin. Apidologie 2000, 31 , 3-15. [CrossRef]

9. Chen, C.N.; Wu, C.L.; Shy, H.S.; Lin, J.K. Cytotoxic prenylflavanones from Taiwanese propolis. J. Nat. Prod. 2003, 66, 503-506. [CrossRef] [PubMed]

10. Chen, C.-N.; Weng, M.-S.; Wu, C.-L.; Lin, J.-K. Comparison of Radical Scavenging Activity, Cytotoxic Effects and Apoptosis Induction in Human Melanoma Cells by Taiwanese Propolis from Different Sources. Evid. Based Complement. Altern. Med. 2004, 1, 175-185. [CrossRef]

11. Chen, C.-N.; Wu, C.-L.; Lin, J.-K. Apoptosis of human melanoma cells induced by the novel compounds propolin A and propolin B from Taiwenese propolis. Cancer Lett. 2007, 245, 218-231. [CrossRef]

12. Huang, W.-J.; Huang, C.-H.; Wu, C.-L.; Lin, J.-K.; Chen, Y.-W.; Lin, C.-L.; Chuang, S.-E.; Huang, C.-Y.; Chen, C.-N. Propolin G, a prenylflavanone, isolated from Taiwanese propolis, induces caspase-dependent apoptosis in brain cancer cells. J. Agric. Food Chem. 2007, 55, 7366-7376. [CrossRef] 
13. Hegazi, A.G.; Hady, F.K.A.E.; Allah, F.A.A. Chemical composition and antimicrobial activity of European propolis. Z. Fur Naturforschung. C J. Biosci. 2000, 55, 70-75. [CrossRef] [PubMed]

14. Sforcin, J.M.; Fernandes, A., Jr.; Lopes, C.A.; Bankova, V.; Funari, S.R. Seasonal effect on Brazilian propolis antibacterial activity. J. Ethnopharmacol. 2000, 73, 243-249. [CrossRef]

15. Grange, J.M.; Davey, R.W. Antibacterial properties of propolis (bee glue). J. R Soc. Med. 1990, 83, 159-160. [CrossRef] [PubMed]

16. Chen, Y.-W.; Wu, S.-W.; Ho, K.-K.; Lin, S.-B.; Huang, C.Y.; Chen, C.-N. Characterisation of Taiwanese propolis collected from different locations and seasons. J. Sci. Food Agric. 2008, 88, 412-419. [CrossRef]

17. Kujumgiev, A.; Tsvetkova, I.; Serkedjieva, Y.; Bankova, V.; Christov, R.; Popov, S. Antibacterial, antifungal and antiviral activity of propolis of different geographic origin. J. Ethnopharmacol. 1999, 64, 235-240. [CrossRef]

18. Yang, H.-Y.; Chang, C.-M.; Chen, Y.-W.; Chou, C.-C. Inhibitory effect of propolis extract on the growth of Listeria monocytogenes and the mutagenicity of 4-nitroquinoline-N-oxide. J. Sci. Food Agric. 2006, 86, 937-943. [CrossRef]

19. Marcucci, M.C.; Ferreres, F.; Custodio, A.R.; Ferreira, M.M.; Bankova, V.S.; Garcia-Viguera, C.; Bretz, W.A. Evaluation of phenolic compounds in Brazilian propolis from different geographic regions. Z. Fur Naturforschung C J. Biosci 2000, 55, 76-81. [CrossRef]

20. Dobrowolski, J.W.; Vohora, S.B.; Sharma, K.; Shah, S.A.; Naqvi, S.A.; Dandiya, P.C. Antibacterial, antifungal, antiamoebic, antiinflammatory and antipyretic studies on propolis bee products. J. Ethnopharmacol. 1991, 35, 77-82. [CrossRef]

21. Bankova, V.S.; Popov, S.S.; Marekov, N.L. A study on flavonoids of propolis. J. Nat. Prod. 1983, 46, 471-474. [CrossRef]

22. Marcucci, M.C. Propolis: Chemical composition, biological properties and therapeutic activity. Apidologie 1995, $26,83-99$. [CrossRef]

23. Ghisalberti, E.L. Propolis: A review. Bee World 1979, 60, 59-84. [CrossRef]

24. Burdock, G.A. Review of the biological properties and toxicity of bee propolis (propolis). Food Chem. Toxicol. 1998, 36, 347-363. [CrossRef]

25. Alencar, S.M.; Oldoni, T.L.; Castro, M.L.; Cabral, I.S.; Costa-Neto, C.M.; Cury, J.A.; Rosalen, P.L.; Ikegaki, M. Chemical composition and biological activity of a new type of Brazilian propolis: Red propolis. J. Ethnopharmacol. 2007, 113, 278-283. [CrossRef]

26. Castro, M.L.; Vilela, W.R.; Zauli, R.C.; Ikegaki, M.; Rehder, V.L.G.; Foglio, M.A.; de Alencar, S.M.; Rosalen, P.L. Bioassay guided purification of the antimicrobial fraction of a Brazilian propolis from Bahia state. BMC Complement. Altern. Med. 2009, 9, 25. [CrossRef]

27. Duarte, S.; Koo, H.; Bowen, W.H.; Hayacibara, M.F.; Cury, J.A.; Ikegaki, M.; Rosalen, P.L. Effect of a novel type of propolis and its chemical fractions on glucosyltransferases and on growth and adherence of mutans streptococci. Biol. Pharm. Bull. 2003, 26, 527-531. [CrossRef]

28. Thirugnanasampandan, R.; Raveendran, S.B.; Jayakumar, R. Analysis of chemical composition and bioactive property evaluation of Indian propolis. Asian Pac. J. Trop. Biomed. 2012, 2, 651-654. [CrossRef]

29. Şahinler, N.; Kaftanoglu, O. Natural product propolis: Chemical composition. Nat. Prod. Res. 2005, 19, 183-188. [CrossRef]

30. Hegazi, A.G.; Hady, F.K.E.A. Egyptian propolis: 1-antimicrobial activity and chemical composition of Upper Egypt propolis. Z. Fur Naturforschung C J. Biosci 2001, 56, 82-88. [CrossRef]

31. Hegazi, A.G.; Hady, F.K.A.E. Egyptian propolis: 3. Antioxidant, antimicrobial activities and chemical composition of propolis from reclaimed lands. Z. Fur Naturforschung C J. Biosci. 2002, 57, 395-402. [CrossRef]

32. Popova, M.; Dimitrova, R.; Al-Lawati, H.T.; Tsvetkova, I.; Najdenski, H.; Bankova, V. Omani propolis: Chemical profiling, antibacterial activity and new propolis plant sources. Chem. Cent. J. 2013, 7, 158. [CrossRef]

33. Bankova, V.; Bertelli, D.; Borba, R.; Conti, B.J.; da Silva Cunha, I.B.; Danert, C.; Eberlin, M.N.; Falcão, S.I.; Isla, M.I.; Moreno, M.I.N.; et al. Standard methods for Apis mellifera propolis research. J. Apic. Res. 2019, 58, 1-49. [CrossRef]

34. Romero, M.; Freire, J.; Pastene, E.; García, A.; Aranda, M.; González, C.; Da Silva, C.C.F.; Salatino, A.; Da Motta, L.B.; Negri, G.; et al. Propolis polyphenolic compounds affect the viability and structure of Helicobacter pylori in vitro. Rev. Bras. Farmacogn. 2019, 29, 325-332. [CrossRef]

35. Melton, L.M.; Taylor, M.J.; Flynn, E.E.; Reid, K.; Viezens, K.J.; Vyas, D.S.; Wilson, A.T. Utilisation of LC/MSMS (QTRAP) and polarity switching for the quantitative analysis of over 300 pesticides in crude QuEChERs extracts from various fruit and vegetable matrices. Chromatography Today. 2018, pp. 28-33. Available online: https://www.chromatographytoday.com/article/lc-ms/48 / science-and-advice-for-scottish-agriculture-sasa/putilisation-of-lcmsms-qtrap-and-polarity-switching-for-the-quantitativeanalysis-of-over-300-pesticides-in-crude-quechers-extracts-from-various-fruit-and-vegetable-matricesnbspp/2334 (accessed on 15 December 2019).

36. Etoxazole; Pesticide Tolerance. Available online: https://www.federalregister.gov/documents/2016/07/27/2016-17786/ etoxazole-pesticide-tolerance (accessed on 15 November 2019).

37. Pesticide Fact Sheet: Fenpropimorph: New Chemical Tolerance Established. Available online: https:/ /www3.epa.gov / pesticides / chem_search/reg_actions/registration/fs_PC-121402_01-Mar-06.pdf (accessed on 15 November 2019).

38. Prevention, Pesticides and Toxic Substances (7508C): Report of the Food Quality Protection Act (FQPA) Tolerance Reassessment Progress and Risk Management Decision (TRED) for Desmedipham. Available online: https:/ /www3.epa.gov/pesticides / chem_ search/reg_actions/reregistration/tred_PC-104801_25-Jan-05.pdf (accessed on 15 December 2019).

39. Method 1657: The Determination of Organo-Phosphorus Pesticides in Municipal and Industrial Wastewater. Available online: https:/ / nepis.epa.gov/Exe/ZyPDF.cgi/P100YX0D.PDF?Dockey=P100YX0D.PDF (accessed on 15 November 2019). 
40. da Silva, J.F.M.; Souza, M.C.; Matta, S.R.; Andrade, M.R.; Vidal, F.V.N. Correlation analysis between phenolic levels of Brazilian propolis extracts and their antimicrobial and antioxidant activities. Food Chem. 2006, 99, 431-435. [CrossRef]

41. Ahn, M.-R.; Kumazawa, S.; Usui, Y.; Nakamura, J.; Matsuka, M.; Zhu, F.; Nakayama, T. Antioxidant activity and constituents of propolis collected in various area of China. Food Chem. 2007, 101, 1383-1392. [CrossRef]

42. Kocot, J.; Kielczykowska, M.; Luchowska-Kocot, D.; Kurzepa, J.; Musik, I. Antioxidant Potential of Propolis, Bee Pollen, and Royal Jelly: Possible Medical Application. Oxid. Med. Cell. Longev. 2018, 2018, 7074209. [CrossRef] [PubMed]

43. Mărghitaş, L.A.; Laslo, L.; Dezmirean, D.; Moise, A.; Maghear, O. Total phenolics and antioxidant activity of Romanian propolis. In Proceedings of the International Conference Agricultural and Food Sciences, Progresses and Technologies, Sibiu, Romania, 2007; pp. 209-212.

44. Moreira, L.; Dias, L.G.; Pereira, J.A.; Estevinho, L. Antioxidant properties, total phenols and pollen analysis of propolis samples from Portugal. Food Chem. Toxicol. 2008, 46, 3482-3485. [CrossRef] [PubMed]

45. Denisow, B.; Denisow-Pietrzyk, M. Biological and therapeutic properties of bee pollen: A review. J. Sci. Food Agric. 2016, 96, 4303-4309. [CrossRef] [PubMed]

46. Russo, A.; Longo, R.; Vanella, A. Antioxidant activity of propolis: Role of caffeic acid phenethyl ester and galangin. Fitoterapia 2002, 73 (Suppl. 1), S21-S29. [CrossRef]

47. Cotelle, N.; Bernier, J.-L.; Catteau, J.-P.; Pommery, J.; Wallet, J.-C.; Gaydou, E.M. Antioxidant properties of hydroxyflavones. Free Radic. Biol. Med. 1996, 20, 35-43. [CrossRef]

48. Werns, S.W.; Lucchesi, B.R. Free radicals and ischemic tissue injury. TIPS 1990, 11, 161-166. [CrossRef]

49. Van Hoorn, D.E.; Nijveldt, R.J.; Van Leeuwen, P.A.; Hofman, Z.; M 'Rabet, L.; De Bont, D.B.; Van Norren, K. Accurate prediction of xanthine oxidase inhibition based on the structure of flavonoids. Eur. J. Pharmacol. 2002, 451, 111-118. [CrossRef]

50. Nile, S.H.; Park, S.W. Total phenolics, antioxidant and xanthine oxidase inhibitory activity of three colored onions (Allium cepa L.). Front. Life Sci. 2013, 7, 224-228. [CrossRef]

51. Elagbar, Z.A.; Naik, R.R.; Shakya, A.K.; Bardaweel, S.K. Fatty Acids Analysis, Antioxidant and Biological Activity of Fixed Oil of Annona Muricata L. Seeds. J. Chem. 2016, 2016, 1-6. [CrossRef]

52. Halub, B.; Shakya, A.K.; Elagbar, Z.A.; Naik, R.R. GC-MS analysis and biological activity of essential oil of fruits, needles and bark of Pinus Pinea grown wildly in Jordan. Acta Pol. Pharm. Drug Res. 2019, 76, 825-831.

53. Arimboor, R.; Rangan, M.; Aravind, S.G.; Arumughan, C. Tetrahydroamentoflavone (THA) from Semecarpus anacardium as a potent inhibitor of xanthine oxidase. J. Ethnopharmacol. 2011, 133, 1117-1120. [CrossRef] [PubMed] 